\title{
Sistem Informasi Deteksi Dini Gas Amonia di Lingkungan Peternakan menggunakan Perangkat Wireless Sensor Network
}

\author{
Imam Ahmad Ashari ${ }^{1 \varpi)}$, Retno Agus Setiawan ${ }^{2)}$, Khoirun Nisa ${ }^{3)}$ \\ ${ }^{1)}$ Program Studi Teknologi Informasi, Universitas Harapan Bangsa, Purwokerto-Indonesia \\ imamahmadashari@uhb.ac.id \\ 2)Program Studi Sistem Informasi, Universitas Harapan Bangsa, Purwokerto-Indonesia \\ retnoagussetiawan@uhb.ac.id \\ 3) Program Studi Informatika, Universitas Harapan Bangsa, Purwokerto-Indonesia \\ khoirunnisa@uhb.ac.id
}

\begin{abstract}
Ammonia is a dangerous gas produced by poultry droppings in the digestive environment. When reaching a certain concentration level of ammonia gas can cause death for birds and even for the breeders themselves. To overcome this, it is necessary to take action to determine the concentration of ammonia gas in the livestock environment in advance. Wireless Sensor Network (WSN) is a solution to this problem, with WSN devices, the concentration of ammonia gas in the farm environment can be monitored in real time. To display data taken from the WSN device in this study the interface uses a web-based graphic visualization. The wireless sensor network design is going well. Data can be retrieved in real time and displayed in a web-based information system with graphical visualization.
\end{abstract}

Keywords - ammonia, wireless sensor networks, information systems, livestock environment

Intisari-Amonia merupakan gas berbahaya yang di hasilkan oleh kotoran unggas di lingkungan peternaan. Ketika mencapi kadar konsentrasi tertentu gas ammonia dapat menyebabkan kematian bagi unggas bahkan untuk peternaknya sendiri. Untuk mengatasi hal tersebut perlu adanya tindakan untuk mengetahui lebih dini kadar konsentrasi gas ammonia yang ada di lingkungan peternakan. Wireless Sensor Network (WSN) merupakan solusi dari masalah itu, dengan perangkat WSN kadar konsentrasi gas ammonia di lingkungan peternakan dapat di monitoring secara realtime. Untuk menampilkan data yang di ambil dari perangkat WSN pada penelitian ini interface menggunkan visualisasi grafik berbasis web. Adapun perancangan wireless sensor network berjalan dengan baik. Data dapat di ambil secara realtime dan di tampilkan dalam system informasi berbasis web dengan visualisasi berbentuk grafik. Hasil penelitian menunjukkan bahwa kondisi ammonia di lingkungan peternakan mempunyai kadar ammonia $<5 \mathrm{ppm}$, yang artinya aman dan tidak membahayakan hewan ternak maupun petugas peternakan di lingkungan tersebut.
Kata kunci-amonia, wireless sensor network, sistem informasi, lingkungan peternakan

\section{PENDAHULUAN}

Gas Amonia $\left(\mathrm{NH}_{3}\right)$ merupakan salah satu contributor utama pembentukan materi partikulat sekunder (PM2.5), yang merupakan risiko yang parah bagi kesehatan manusia [1]. Amonia $\left(\mathrm{NH}_{3}\right)$ merupakan gas yang di timbulkan oleh salah satunya yaitu kotoran unggas di lingkungan peternakan. Gas amonia menjadi gangguan bagi penduduk di lingkungan sekitar peternakan sehingga di sebut sebagai polusi pada skala regional [2]. Gas amonia tidak berwarna, sangat beracun dengan bau yang menyengat dan membahayakan tubuh manusia karena berpotensi mempengaruhi sistem kekebalan atau menghambat pertumbuhan sel [3]. 25 ppm adalah batas konsentrasi untuk orang yang terpapar selama 8 jam per hari, dan $35 \mathrm{ppm}$ adalah batas konsentrasi untuk orang yang terpapar $\mathrm{NH}_{3}$ selama 15 menit [4]. Untuk dapat mengantisipasi hal itu terjadi perlu adanya perangkat yang mampu mendeteksi secara dini konsentrasi gas ammonia di peternakan secara realtime.

Baru-baru ini, Wireless Sensor Networks (WSN) telah menarik banyak perhatian karena kegunaannya yang hebat di bidang Internet of Things [5]. Salah satunya adalah penggunaan WSN untuk monitoring polusi di rute perkotaan [6]. Di antara metode pengambilan data gas $\mathrm{NH}_{3} \mathrm{WSN}$ adalah yang paling umum digunakan untuk deteksi karena kesederhanaan dan kenyamanannya [7]. Untuk menampilkan data yang di ambil secara realtime penelitian ini menyediakan system informasi berbasis web. Sistem informasi menampilkan visualisasi grafik perubahan gas ammonia di lingkungan peternakan secara realtime. Selain visualisasi grafik, agar informasi lebih mudah di akses notifikasi bahaya juga di kirim melalui bot telegram. 


\section{METODELOGI}

\section{A. Perancangan Wireless Sensor Network}

Untuk mengambil data amonia secara realtime penelitian ini menggunakan model sistem akuisisi data sensor. Sistem akuisisi data sensor dilakukan untuk mendapatkan nilai kadar konsentrasi gas amonia secara langsung dan realtime di lapangan. Penelitian menggunakan sensor MQ-135 dengan tegangan analog sebesar $0-5 \mathrm{~V}$ dan diterjemahkan dalam bilangan biner 0-1024 melalui ADC. Komunikasi data serial ini dilakukan antara mikrokontroler dengan sebuah PC menggunakan protokol RS232 yang akan mengubah level tegangan yang bisa dibaca oleh mikrokontroler.

Ada beberapa bagian yang perlu dirancang terlebih dahulu untuk mendesain WSN deteksi kadar gas amonia ini. Pada bagian Remote Terminal Unit (RTU) terdiri dari penyangga yaitu tiang utama, kotak besi sebagai tempat peralatan untuk pengambilan data kadar gas amonia, tabung besi sebagai tempat sensor gas dan tiang pemancar WiFi.

Dalam sistem pemantauan kadar gas amonia ini terdapat stasiun pengamatan yang bekerja sebagai pusat pemantauan data yang didapat dari titik pemantauan di lapangan. Pada bagian sistem Control Terminal Unit (CTU) ini berada terpisah dari titik pemantauan. Peralatan yang dibutuhkan untuk membangun sistem RTU terdiri dari sebuah PC (personal computer), WiFi dan MiFi (Modem WiFi).

WiFi digunakan sebagai penerima sinyal dari titik pemantauan, bekerja sebagai penerima data kadar gas amonia. Untuk menyimpan data kadar gas amonia ke dalam cloud base pastikan $\mathrm{WiFi}$ terkoneksi dengan $\mathrm{MiFi}$. Selanjutnya gunakan pemrograman MQTT untuk membaca dan menyimpan data ke dalam ke cloud base. Data-data yang disimpan selanjutnya dilakukan perhitungan lebih lanjut dengan menggunakan metode Inverse Distance Weight (IDW). Dari data yang telah diterima akan ditampilkan pada sebuah PC menggunakan web browser yang dapat diakses dari PC tersebut dengan cara memasukkan alamat domain sistem. Rancangan arsitektur WSN deteksi bahaya kadar konsentrasi gas amonia bisa dilihat pada gambar 1 .

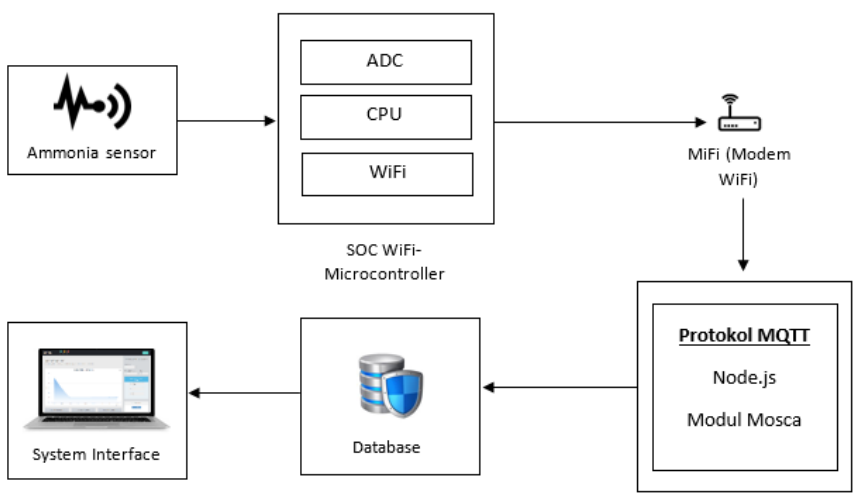

Gambar 1. Arsitektur wireless sensor network untuk pengambilan data ammonia

\section{B. Konversi Data Sensor}

Untuk mendapatkan kadar konsentrasi gas amonia dalam satuan ppm (part per million) perlu dilakukan konversi untuk mengubah tegangan sensor dari nilai bit menjadi ppm. Untuk melakukan konversi kadar gas amonia gunakan persamaan berikut [8]:

$$
\mathrm{PPM}=(6,8323 /(\mathrm{Rs} / \mathrm{Ro})) \text { 2,457 }
$$

Untuk menyimpan data kadar konsentrasi gas amonia lakukan akuisisi data sensor. Akuisisi data sensor digunakan untuk mendapatkan nilai kadar konsentrasi gas amonia. Proses akuisisi data merubah tegangan analog sebesar 0-5 V ke dalam bilangan biner 0-1024 melalui ADC. Tegangan analog dikonversi menjadi nilai kadar konsentrasi gas amonia dalam satuan ppm. Proses akuisisi data dilakukan dalam interval waktu 2 menit sekali. Proses pengambilan data dilakukan selama 9 jam dari mulai pukul $11.00 \mathrm{~s} / \mathrm{d}$ 08.00. Untuk mengakuisisi data hasil pembacaan ADC dari sensor MQ-135 gunakan persamaan berikut [8]:

$$
\mathrm{ppm}=\text { power }(\mathrm{Rs} / \mathrm{Ro}), 2.457
$$

\section{HASIL DAN PEMBAHASAN}

Pengambilan ammonia di lakukan di 3 titik, titik 1 di kandang bagian depan, titik 2 kandang bagian tengah dan titik 3 di kandang bagian belakang. Dari pengambilan data di ketiga titik tersebut di hasilkan data sebagai berikut:

\begin{tabular}{|c|c|c|c|}
\hline No & $\begin{array}{c}\text { Titik } \\
\text { Pengambilan }\end{array}$ & ppm & Waktu Pengambilan \\
\hline 1 & 1 & 0.1433421 & 07/07/2019 3:25 \\
\hline 2 & 2 & 2.08840323 & 07/07/20193:25 \\
\hline 3 & 1 & 0.25918194 & 07/07/2019 3:27 \\
\hline 4 & 3 & 0.8888069 & 07/07/2019 3:25 \\
\hline 5 & 1 & 0.28757478 & 07/07/2019 3:29 \\
\hline 6 & 2 & 3.56717514 & 07/07/2019 3:27 \\
\hline 7 & 1 & 0.19819451 & 07/07/20193:31 \\
\hline 8 & 2 & 2.43257312 & 07/07/2019 3:29 \\
\hline 9 & 3 & 0.9493625 & 07/07/2019 3:27 \\
\hline 10 & 2 & 3.52833757 & 07/07/2019 3:31 \\
\hline 11 & 1 & 0.4740763 & 07/07/20193:33 \\
\hline 12 & 3 & 0.5261819 & 07/07/2019 3:29 \\
\hline 13 & 2 & 2.82229535 & 07/07/2019 3:33 \\
\hline 14 & 3 & 0.9135656 & 07/07/2019 3:31 \\
\hline 15 & 1 & 0.0728436 & 07/07/2019 3:35 \\
\hline 16 & 3 & 0.6546321 & 07/07/2019 3:33 \\
\hline 17 & 2 & 2.22670883 & 07/07/2019 3:35 \\
\hline 18 & 1 & 0.41539537 & 07/07/2019 3:37 \\
\hline 19 & 1 & 0.43148597 & 07/07/2019 3:39 \\
\hline 20 & 2 & 2.66364342 & 07/07/2019 3:37 \\
\hline 21 & 1 & 0.4433749 & 07/07/2019 3:41 \\
\hline 22 & 2 & 3.25829243 & 07/07/20193:39 \\
\hline 23 & 3 & 0.56588 & 07/07/20193:35 \\
\hline 24 & 1 & 0.41677362 & 07/07/2019 3:43 \\
\hline 25 & 2 & 3.21404806 & 07/07/20193:41 \\
\hline
\end{tabular}

TABLE I. $\quad 40$ DATA AMONIA 


\begin{tabular}{|c|c|c|c|}
\hline 26 & 3 & 0.6210845 & $07 / 07 / 20193: 37$ \\
\hline 27 & 2 & 2.06665379 & $07 / 07 / 20193: 43$ \\
\hline 28 & 1 & 0.30567762 & $07 / 07 / 20193: 45$ \\
\hline 29 & 2 & 2.64748654 & $07 / 07 / 20193: 45$ \\
\hline 30 & 3 & 0.6743228 & $07 / 07 / 20193: 39$ \\
\hline 31 & 2 & 2.37320716 & $07 / 07 / 20193: 47$ \\
\hline 32 & 3 & 0.7143957 & $07 / 07 / 20193: 41$ \\
\hline 33 & 1 & 0.01366712 & $07 / 07 / 20193: 47$ \\
\hline 34 & 2 & 3.89798523 & $07 / 07 / 20193: 49$ \\
\hline 35 & 3 & 0.8439921 & $07 / 07 / 20193: 43$ \\
\hline 36 & 1 & 0.35215101 & $07 / 07 / 20193: 49$ \\
\hline 37 & 2 & 2.55952171 & $07 / 07 / 20193: 51$ \\
\hline 38 & 3 & 0.8618265 & $07 / 07 / 20193: 45$ \\
\hline 39 & 2 & 2.91261288 & $07 / 07 / 20193: 53$ \\
\hline 40 & 3 & 0.4259893 & $07 / 07 / 20193: 47$ \\
\hline
\end{tabular}

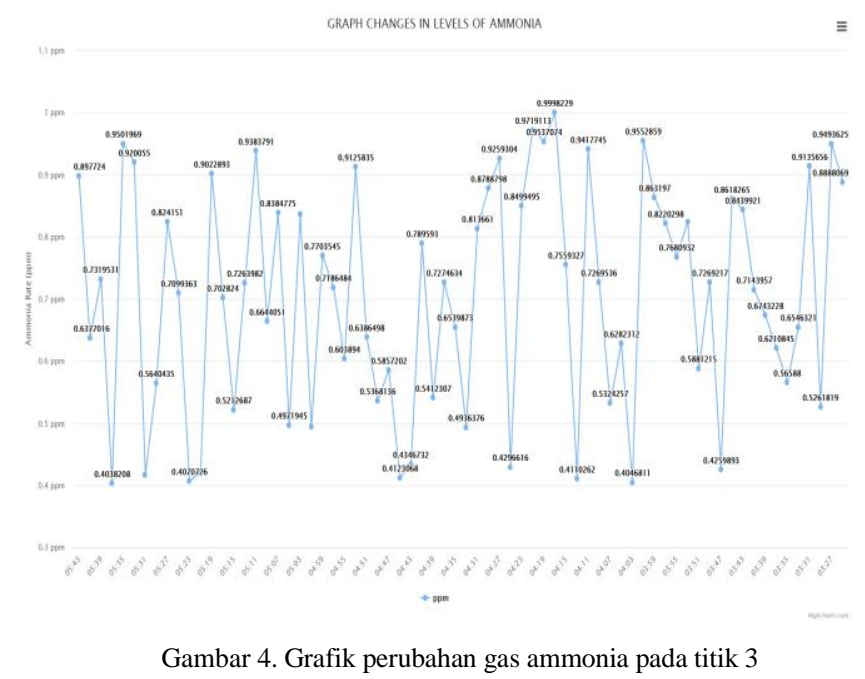

Dari data ammonia yang di ambil secara realtime di tampilkan ke dalam system informasi dengan visualisasi grafik. Gambar visualisasi grafik perubahan ammonia bisa di lihat pada gambar berikut.

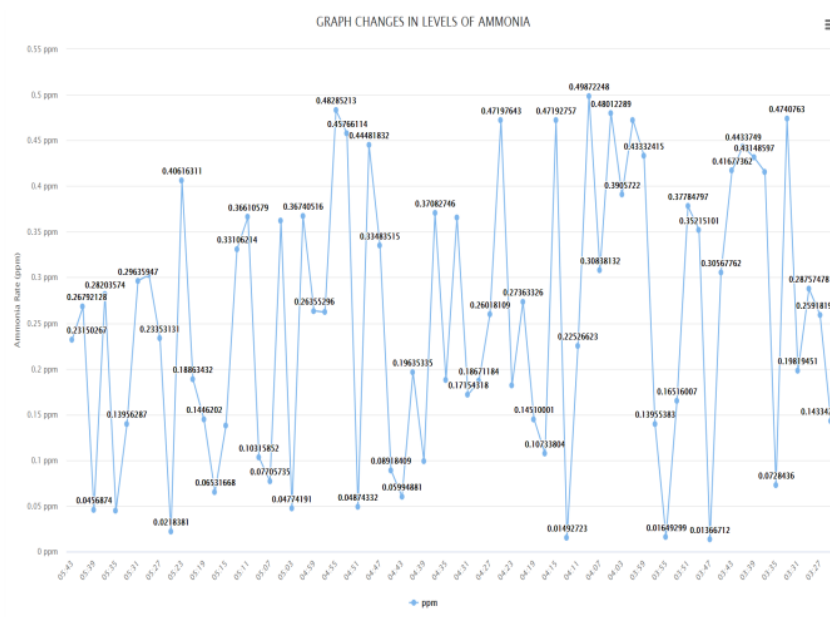

Gambar 2. Grafik perubahan gas ammonia pada titik 1

Selain di tampilkan dalam bentuk grafik, notifikasi bahaya ammonia juga di tampilkan dalam bentuk notifikasi via social media elegram .Untuk simulasi bahaya notifikasi via telegaram bisa di lihat pada gambar beriku.
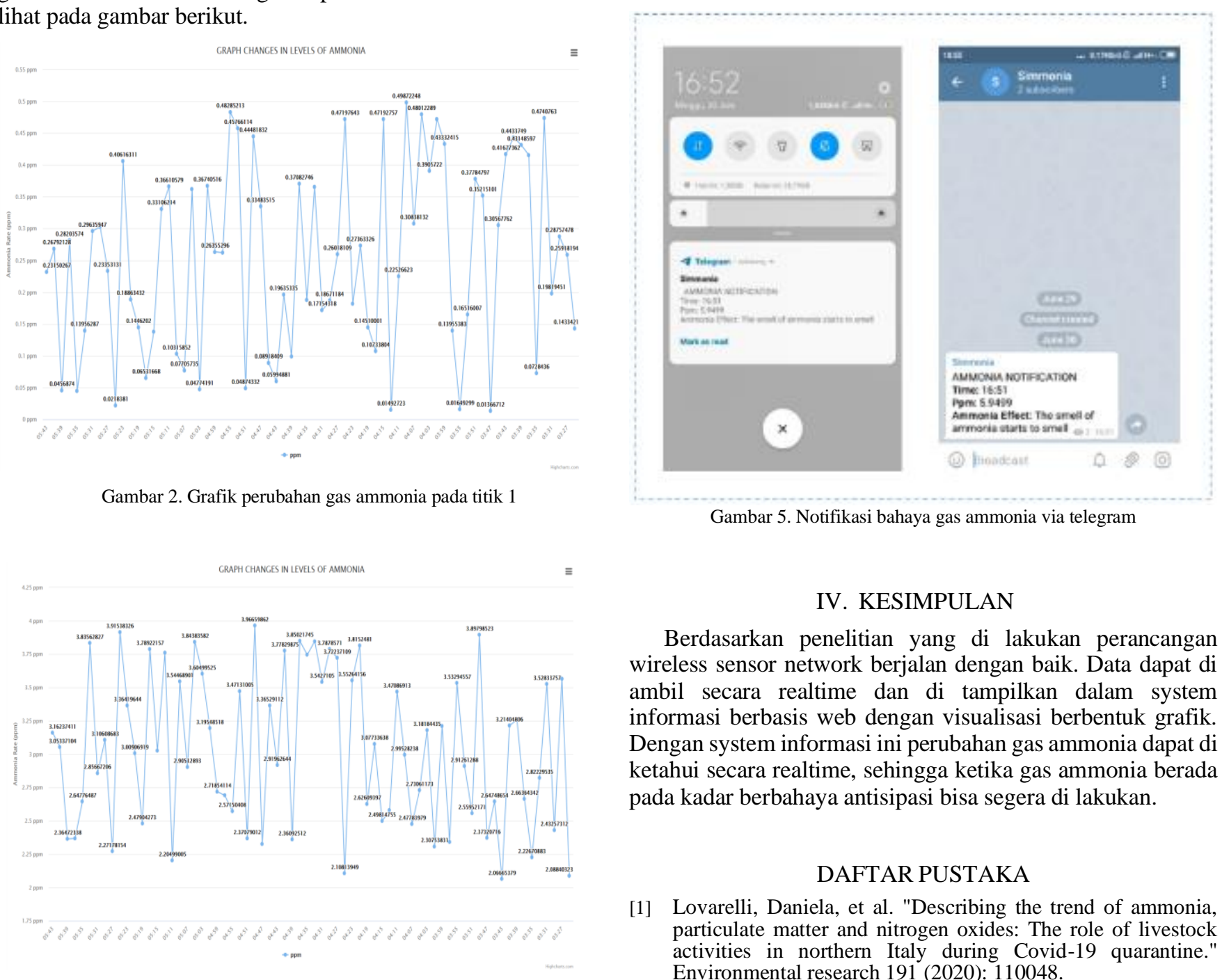

\section{KESIMPULAN}

Berdasarkan penelitian yang di lakukan perancangan wireless sensor network berjalan dengan baik. Data dapat di ambil secara realtime dan di tampilkan dalam system informasi berbasis web dengan visualisasi berbentuk grafik. Dengan system informasi ini perubahan gas ammonia dapat di ketahui secara realtime, sehingga ketika gas ammonia berada pada kadar berbahaya antisipasi bisa segera di lakukan.

\section{DAFTAR PUSTAKA}

[1] Lovarelli, Daniela, et al. "Describing the trend of ammonia, particulate matter and nitrogen oxides: The role of livestock activities in northern Italy during Covid-19 quarantine." Environmental research 191 (2020): 110048. 
[2] Schauberger, Günther, et al. "Impact of global warming on the odour and ammonia emissions of livestock buildings used for fattening pigs." biosystems engineering 175 (2018): 106-114.

[3] Chen, Huawei, et al. "Suspended SnS2 layers by light assistance for ultrasensitive ammonia detection at room temperature." Advanced Functional Materials 28.20 (2018): 1801035 .

[4] ] T. Merian, N. Redon, Z. Zujovic, D. Stanisavljev, J.L. Wojkiewicz, M. GizdavicNikolaidis, Ultra sensitive ammonia sensors based on microwave synthesized nanofibrillar polyanilines, Sens. Actuat B-Chem. 203 (2014) 626-634.

[5] Shaikh, Faisal Karim, and Sherali Zeadally. "Energy harvesting in wireless sensor networks: A comprehensive review."
Renewable and Sustainable Energy Reviews 55 (2016): 10411054.

[6] Ullo, S., et al. "Application of wireless sensor networks to environmental monitoring for sustainable mobility." 2018 IEEE International Conference on Environmental Engineering (EE). IEEE, 2018.

[7] Lv, Dawu, et al. "Enhanced flexible room temperature ammonia sensor based on PEDOT: PSS thin film with $\mathrm{FeCl} 3$ additives prepared by inkjet printing." Sensors and Actuators B: Chemical 298 (2019): 126890.

[8] Siswanti, Arlien, and Suryono Suryono. "Wireless Sensor System untuk Pemantauan Kadar Gas Amonia $\left(\mathrm{NH}_{3}\right)$ Menggunakan Algoritma Berbasis Aturan." Youngster Physics Journal 5.2 (2016): 59 